\title{
Um estudo sobre o pensamento social de jovens universitários acerca da justiça e das cotas raciais
}

\author{
A study on the social thinking of university students about justice and racial quotas
}

\author{
Thamiris Marques ${ }^{1}$ \\ Bruna Kappel Almeida dos Santos ${ }^{2}$
}

\begin{abstract}
RESUMO: Este artigo visa estudar os conceitos de justiça e de cotas raciais de jovens favoráveis, desfavoráveis e neutros em relação às cotas raciais. Para entender a produção de saber referente à frequente rejeição a essa temática recorreu-se ao aporte teórico das Representações sociais. Para tanto, foram entrevistados de forma semiestruturada 14 estudantes divididos em três posicionamentos frente às cotas raciais: favoráveis, desfavoráveis e neutros. A amostra foi composta por estudantes da Universidade do Estado do Rio de Janeiro (UERJ), Universidade Federal de Uberlândia (UFU) e Universidade Federal Rural do Rio de Janeiro (UFRRJ). Os dados foram analisados com uma análise de conteúdo segundo Bardin (2000). A análise das 14 entrevistas obteve um total de 144 unidades de registro contabilizadas e inseridas em 55 unidades de significação que, por sua vez, foram incluídos em 21 categorias. Os resultados demonstram que os participantes de todos os posicionamentos tiveram dificuldade de definir o conceito de justiça. Além disso, ligada à noção de justiça, surge a questão da igualdade, mas focalizada sob aspectos muito distintos para os sujeitos, pois enquanto os favoráveis defendem as cotas enquanto uma medida de promoção da igualdade, os desfavoráveis a criticam por acreditar que estas ferem a mesma. Os sujeitos desfavoráveis, apesar de rejeitarem as cotas para negros, demonstram aceitação das cotas sociais, e os resultados referentes aos participantes neutros demonstram um grau de polifasia cognitiva, uma vez que levantam respostas distintas e contrárias umas às outras típicas, mais precisamente apresentam argumentos dos dois posicionamentos polarizados referentes às cotas.
\end{abstract}

Palavras-chaves: cotas para negros; justiça; representações sociais.

ABSTRACT: This article aims to study the concepts of justice and racial quotas favorable, unfavorable and neutral young people in relation to racial quotas. To understand the production of knowledge regarding the frequent rejection of this theme, we used the theoretical framework of social representations. Therefore, the interview was made in a semi-structured form with 14 students divided into three positions about racial quotas: favorable, unfavorable or neutral. The sample consisted of students from Rio de Janeiro State University (UERJ), Federal University of Uberlandia (UFU) and Federal University Rural Rio de Janeiro (UFRRJ). Data was analyzed with a content analysis according to Bardin (2000). The analysis of the 14 interviews obtained a total of 144 registration units counted and placed in 55 subjects who, in turn, were included in 21-target subjects. The results showed that participants in all positions found it difficult to define the concept of justice. In addition, linked to the notion of justice, the question arises of equality, but focused on very different aspects of the subject, while the favorable advocate quotas as a way of promoting equality, the unfavorable ones criticize it because they believe that these hurt the same. Some of the people who were against the quotas for black people accept the shares of social dimensions, and the results regarding the neutral participants showed a degree of cognitive polyphasia, since they have raised distinct and opposit typical responses. More precisely, the typical responses embrace arguments from both of the polarized positions relating to quotas.

Keywords: quotas for blacks; justice; social representations.

\footnotetext{
1 Psicóloga; Mestranda do Programa de Pós-Graduação em Psicologia Social da Universidade do Estado do Rio de Janeiro Rio de Janeiro, RJ, Brasil. E-mail: thamiris_marques@hotmail.com.

${ }^{2}$ Bolsista de iniciação científica da Universidade do Estado do Rio de Janeiro - Rio de Janeiro, RJ, Brasil.
} 


\section{Introdução}

O presente trabalho busca compreender a possível relação entre as representações sociais e concepções de justiça influenciando o posicionamento de estudantes universitários acerca das cotas para negros nas Universidades públicas. Trata-se de um tema de amplo debate na sociedade, polêmico e inserido no cotidiano dos estudantes universitários por fazer parte do processo de seleção da Universidade.

As políticas de ação afirmativa estão presentes em países de todos os continentes e segundo Munanga (2001, p. 31) "visam oferecer aos grupos discriminados e excluídos um tratamento diferenciado para compensar as desvantagens devidas à sua situação de vítimas do racismo e de outras formas de discriminação".

De uma forma geral, pode-se dizer que são medidas compensatórias que possuem o objetivo prático de promover acesso de determinadas minorias sociais prejudicadas e discriminadas a meios fundamentais como educação e emprego (Bergmann, 1996; Moehlecke, 2002; Sell, 2002; Sandel, 2012).

Para Gomes (2003, p. 11) "as ações afirmativas têm como objetivo não apenas coibir a discriminação do presente, mas sobretudo eliminar os efeitos persistentes (psicológicos, culturais e comportamentais) da discriminação do passado, que tendem a se perpetuar."

Ações afirmativas relacionadas à população negra surgiram na década de 60 , nos Estados Unidos da América durante a presidência de John Kennedy. O objetivo do Estado não era apenas promover leis antissegregacionistas, mas sim trabalhar de forma ativa, criando assim medidas práticas voltadas para melhoria da população negra (Munanga, 2001; Moehlecke, 2002).

As políticas de ações afirmativas abarcam o sistema de cotas, que pode ser definido por Moehlecke (2002, p. 3) como "determinado número ou percentual a ser ocupado em área específica por grupo(s) definido(s), o que pode ocorrer de maneira proporcional ou não, e de forma mais ou menos flexível".

A população negra no Brasil sofre com uma desigualdade histórica. Estes chegaram ao país logo após sua descoberta, por volta de 1511, trazidos do continente africano e servindo como mão-de-obra escrava aos portugueses há décadas antes da vinda à colônia brasileira (Tinhorão, 1988).

Em Portugal os negros possuíam diversas ocupações encaminhadas de seus donos relacionadas a tarefas de casa, como empregados domésticos; ao campo, como lavradores e cuidadores de animais; na cidade, como vendedores e artesãos, etc. (Tinhorão, 1988).

A importância da escravidão dos africanos na incipiente colônia era vital, de forma que em 1587 os negros totalizavam entre $24 \%$ e 34\% da população no Brasil, a saber, entre 15 e 20 mil negros inseridos numa população total de cerca de 60 mil (Tinhorão, 1988).

Nos últimos anos, perto da abolição da escravatura, por volta de 1888, os escravos negros eram 723 mil (Schulz, 1994; Kowarick, 1994). Pela impossibilidade de continuar a servir como escravos ficaram excluídos, tornando-se uma população de mão-de-obra excedente e marginalizada na sociedade. Assim, o negro que possuía um lugar desumano, mas fundamental na economia, após a abolição não só perdeu esse lugar como foi colocado à margem da sociedade sem qualquer tipo de amparo ou possibilidade de ascensão social, o 
que propagou sua situação de pobreza e também miséria às gerações seguintes (Theodoro, 2008).

Além da questão econômica permeando a abolição da escravatura surge também o processo de discriminação do negro que ocorre com frequência em diversas esferas sociais do Brasil (Jaccoud, 2008). A partir disso, surge no Brasil, com o cenário da promulgação da nova constituição e também o centenário da abolição da escravatura nos anos 80 , pressões e exigências das organizações negras frente ao Governo, o que, provavelmente, impulsionou o surgimento de medidas ativas em prol dos negros, a saber, ações afirmativas (Guimarães, 2003). Cabe ressaltar que estas organizações possivelmente agiram como minorias ativas (Moscovici, 1979) ao ter consistência e união no pedido de melhores condições e manter esta consistência no tempo.

Com o lançamento do Programa Nacional dos Direitos Humanos (Universidade de São Paulo, 1996) um dos objetivos estabelecido pela Secretaria de Direitos Humanos foi o desenvolvimento de ações afirmativas relacionadas ao acesso de negros à educação, o que se caracteriza como uma forma de discriminação positiva. Assim, projetos de leis surgiram para atender à determinação da Secretaria de Direitos Humanos, todavia, até então nada havia sido aprovado. Somente a partir de 2001 começaram a ser aprovadas políticas de ação afirmativa, como por exemplo a contratação de $20 \%$ de negros, $20 \%$ de mulheres e $5 \%$ de portadores de deficiência para cargos de assessoramento do Ministério Público (Moehlecke, 2002; Piovesan, 2008).

Em 2000 foi aprovada a Lei no 3.524 que obrigava as universidades estaduais cariocas à reserva de $50 \%$ de vagas para alunos oriundos de escola pública. E em 2001, tanto a UNB quanto a Universidade do Estado do Rio de Janeiro (UERJ) aderiram às cotas raciais (Queiroz \& Santos, 2006; Naiff, Naiff \& Souza, 2009; Lima, Neves \& Silva, 2014). No caso da UERJ foi aprovada a Lei no 3.708/2001, que destinava 40\% das vagas para negros e pardos.

Em 29 de agosto de 2012, foi sancionada pela Presidente Dilma Rousseff a Lei das Cotas/Lei no 12.711, onde:

As instituições federais de educação superior vinculadas ao Ministério da Educação reservarão, em cada concurso seletivo para ingresso nos cursos de graduação, por curso e turno, no mínimo $50 \%$ (cinquenta por cento) de suas vagas para estudantes que tenham cursado integralmente 0 ensino médio em escolas públicas. Parágrafo único. No preenchimento das vagas de que trata o caput deste artigo, 50\% (cinquenta por cento) deverão ser reservados aos estudantes oriundos de famílias com renda igual ou inferior a 1,5 salário-mínimo (um salário-mínimo e meio) per capita. Em cada instituição federal de ensino superior, as vagas de que trata o art. 1으 desta Lei serão preenchidas, por curso e turno, por autodeclarados pretos, pardos e indígenas, em proporção no mínimo igual à de pretos, pardos e indígenas na população da unidade da Federação onde está instalada a instituição, segundo o último censo do Instituto Brasileiro de Geografia e Estatística (IBGE) (BRASIL, 2012).

Dentre os argumentos contrários às cotas raciais existe a ideia de que os próprios negros beneficiados pelas cotas poderiam ter sua imagem profissional prejudicada pelo acesso à universidade por uma reserva de vagas. (Munanga, 2001). Dentre os críticos às cotas raciais podemos com frequência encontrar também o tema da Isonomia, que é a interferência do princípio de igualdade.

Por vezes a crítica às cotas raciais se centra na questão da pobreza ao salientar que a verdadeira questão do problema das minorias é de ordem econômica. A Miscigenação e seu corolário, ou seja, a dificuldade de definir as pessoas por cor (Oliven, 2007; Almeida, 2007) 
aparece nas críticas à operacionalização desta política pública. Alguns professores, por sua vez, se inquietaram com a perda do mérito nas Universidades o que reduziria a qualidade doe estudante formado (Guimarães, 2003).

Aqueles que fazem defesa das cotas raciais alegam a relevância destas por conta da tentativa de proporcionar mais acesso às minorias prejudicadas ao longo da história (Oliven, 2007; Almeida, 2007). Há também a afirmação que tanto os negros quanto os indígenas foram reprimidos no passado e necessitam de medidas para equiparar as desigualdades históricas (Oliven, 2007). Alguns argumentos se centram na lógica de que ser branco no Brasil é mais fácil que ser negro e indígena, logo o Estado precisa intervir em favor dessas minorias (Oliven, 2007).

\section{Campo de estudos das Representações Sociais}

Este trabalho se situa no campo de estudos das Representações Sociais onde se estuda o pensamento de senso comum acerca de objetos da realidade social. Esse campo foi inaugurado por Serge Moscovici ao elaborar sua tese de doutorado intitulada La Psychanalyse, son image et son public, orientada por Lagache e publicada em 1961 na França (Sá, 1993; Shimizu \& Menin, 2004; Spadoni \& Torres, 2010; Wolter, 2011).

Em sua tese o autor estava interessado em saber como a psicanálise era percebida pelos franceses, mais precisamente como comunistas e católicos entendiam a psicanálise. Outro objetivo era verificar como o saber reificado, um saber acadêmico, douto, entrava no universo consensual, senso comum. Em outras palavras o que Moscovici buscou, de uma forma geral, foi saber a procedência de construção de um mundo significante e, de uma forma específica, saber como é apropriada pelas pessoas uma teoria científica (Vala \& Monteiro, 2000).

A lógica pela qual as representações são elaboradas é para que se possa compreender o mundo e também para saber se comportar e se posicionar a ele. Uma característica é que fornecem uma visão funcional do mundo orientando as atitudes e comportamentos (Moscovici, 1978). Assim elas direcionam e auxiliam nos processos referentes à tomada de posição (Jodelet, 2001).

Diferentemente do saber científico, as representações sociais estão situadas no saber natural, ingênuo. Elas constituem uma forma de saber, de conhecer do mundo. Estão sempre relacionadas à forma como o sujeito se relaciona com objeto, e sua relação é tão intrínseca que na ausência do objeto não há representação. Com relação a sua natureza, este pode ser real ou fictício, concreto ou abstrato. Sendo assim, o objeto pode ser tanto uma pessoa quanto uma teoria, tanto um acontecimento quanto uma ideia (Jodelet, 2001).

Ao falar de representação social Moscovici ressalta que não há pura e simples reprodução ou repetição da realidade. Ao contrário, tanto o conceito transforma a percepção quanto esta implica na mudança do conceito (Sá, 1993). Trata-se da construção de uma representação a partir do movimento mútuo entre ambos. Esta noção é ressaltada por Vala e Monteiro (2000), onde o processamento de informação também é visto de uma forma distinta da reprodução de informações, mas ao contrário, é construído e teoriza a realidade. 
Abric (2000) também ressalta esta não reprodução imediata e automática do conteúdo percebido da realidade, mas sim uma apropriação desta por meio da representação, processo esse ligado à história do grupo e também do objeto. Assim, para cada grupo e os indivíduos que o compõem há uma realidade própria ligada a seus valores e ideologia, ligada a sua história.

Denise Jodelet definiu as representações sociais como "uma forma de conhecimento, socialmente elaborada e partilhada, tendo uma visão prática e concorrendo para a construção de uma realidade comum a um conjunto social” (Jodelet, 2001, p. 22).

Já Jean-Claude Abric (2000, p.28), as define da seguinte forma:

A representação funciona como um sistema de interpretação da realidade que rege as relações dos indivíduos com o seu meio físico e social, ela vai determinar seus comportamentos e suas práticas. A representação é um guia para a ação, ela orienta as ações e a s relações sociais. Ela é um sistema de pré-codificação da realidade porque ela determina um conjunto de antecipações e expectativas.

De uma forma geral as representações sociais vêm do senso comum, sendo conhecimentos construídos e elaborados nos universos consensuais que, na maioria das vezes, são versões dos universos reificados (Sá, 2007). Moscovici (1978) ressalta que não há uma representação social verdadeira, certa, mas sim várias representações que variam de acordo com os grupos que as abarcam. São saberes únicos ligados à história do grupo e a forma como eles constroem e ao mesmo tempo veem a realidade.

Dentre as funções das representações pode-se citar: função saber, que é a busca pela compreensão e explicação da realidade onde a representação social constitui uma teoria do senso comum acerca da realidade; função identitária, na qual as identidades são definidas pelas representações; função de orientação, onde tanto os comportamentos quanto as atitudes são guiadas pelas representações constituindo um guia para as ações envolvendo o objeto representado; e função justificadora, cuja representação possibilita justificar por que esta ou aquela decisão foi tomada (Abric, 2000).

\section{Concepções de Justiça e cotas}

Existe uma grande dificuldade em definir o que é justo e injusto. $O$ que se sabe é que o conceito de Justiça é pertinente em toda sociedade e também possui um valor muito importante, pois em nome da justiça diversos grupos sociais demandam ações que sejam condizentes com seus posicionamentos. Sandel (2012) aponta que sociedade justa é aquela que distribui o que valoriza entre os indivíduos, por exemplo: riquezas, poderes, direitos, deveres, oportunidades, etc. Ele afirma que as dificuldades e dissensões começam justamente ao definir e justificar o que é fundamental a essa distribuição.

Três abordagens da Justiça são exploradas pelo autor: a primeira possui como ideia central a maximização do bem-estar ou felicidade, também conhecido como utilitarismo; a segunda aborda justiça atrelada à noção de liberdade e a terceira, justiça ligada à virtude e boa vida. Esta última costuma estar vinculada à direita religiosa e conservadores (Sandel, 2012).

No âmbito filosófico, o que é justo ou injusto pode estar relacionado a dois parâmetros, às ações das pessoas ou às normas. Com relação às ações, temos alguém por justo ou injusto de acordo com a forma como a norma é ou não aplicada por este, e também 
pela possibilidade deste fazer algum tipo de discriminação fora da norma não justificada (Velasco, 2009).

Dentro dessa perspectiva, ser justo é tratar a todos os que estão sob determinada norma de forma igualitária. A proximidade e ligação entre os conceitos de justiça e igualdade existe desde Aristóteles, que afirmava que ser justo é tratar de forma igual (Velasco, 2009). Em sua teoria da justiça Aristóteles postula que a justiça é teleológica e honorífica, ou seja, para ser justo é preciso considerar a finalidade da situação em questão e buscar entender o que deve ser recompensado dentro desta (Sandel, 2012).

Teorias de justiça mais antigas partem da noção de virtude (Sandel, 2012), enquanto teorias contemporâneas concordam que para haver justiça é necessário igualdade (Neves \& Lima, 2007). As divergências com relação aos conceitos de justiça começam quando se tenta delimitar o meio pelo qual a igualdade será garantida.

A noção de igualdade surgiu com base no contato de ideias dos EUA e França, e visa abolir qualquer tipo de discriminação e privilégio voltados para linhagem e hierarquia social (Gomes, 2003). O que Gomes (2003) ressalta é que esta noção de igualdade é fictícia, pois passou a ser questionada a partir do momento em que foi verificada a necessidade de acesso a grupos de pessoas prejudicados socialmente. A partir de tais considerações, surge a noção de igualdade substancial, ao invés do conceito estático derivado dos estadunidenses e franceses. E a partir dele são permitidas distinções a fim de equiparar as desigualdades da população e proporcionar a justiça social.

Piovesan (2008, p. 888) apresenta três vertentes de concepções de igualdade:

\begin{abstract}
a) a igualdade formal, reduzida à fórmula "todos são iguais perante a lei" (que, ao seu tempo, foi crucial para abolição de privilégios); b) a igualdade material, correspondente ao ideal de justiça social e distributiva (igualdade orientada pelo critério socioeconômico); e c) a igualdade material, correspondente ao ideal de justiça enquanto reconhecimento de identidades (igualdade orientada pelos critérios de gênero, orientação sexual, idade, raça, etnia e demais critérios).
\end{abstract}

Com base nessas definições autores como Nancy Fraser (2002) e Boaventura de Sousa Santos (2008) adotam como exigência fundamental para haver justiça a redistribuição e o reconhecimento das diferentes identidades, conduzindo assim à igualdade. Ou seja, a justiça seria contemplada a partir de medidas de enfrentamento à injustiça cultural e econômica. (Piovesan, 2008).

De fato, abordada tanto por posicionamentos contrários quanto favoráveis as cotas a noção de igualdade se difere de acordo com a perspectiva adotada. Os contrários tomam a noção de igualdade como oposta ao privilégio, enquanto os favoráveis a veem como igualdade de oportunidades, sendo oposta à meritocracia. A primeira perspectiva se refere a um conceito abstrato de igualdade, já a segunda traz um conceito substancial do conceito (Pinto, 2005).

Dentro dessa perspectiva a igualdade substancial pode ser vista como uma tentativa de tornar concreta uma igualdade populacional tão abstrata. Tal concretude se dá através das discriminações positivas ou ações afirmativas (Gomes, 2003).

Embora os posicionamentos contrários às ações afirmativas, e mais precisamente às cotas, afirmem que estas ferem o princípio de igualdade presente na Constituição Federal art. 5ㅇ, que diz que "todos são iguais perante a lei, sem distinção de qualquer natureza". Cabe ressaltar que esta mesma Constituição Federal diz no art. 3ㅇ que "Constituem objetivos 
fundamentais da República Federativa do Brasil: I - construir uma sociedade livre, justa e solidária; e III - erradicar a pobreza e a marginalização e reduzir as desigualdades sociais e regionais".

Com isso pode-se dizer que a Constituição não só defende a igualdade como também, por outro lado, assegura que a sociedade deve ser justa e erradicar a desigualdade, o que permite que sejam elaboradas medidas, como as ações afirmativas, que garantam a implementação dessa igualdade substancial (Gomes, 2003).

É importante ressaltar que ao mencionar Justiça a alguém estamos sempre falando de alguém em um grupo, ou seja, alguém que possui semelhanças com outras pessoas e por isso se encontra nesse grupo. Apesar de haver semelhança isso não os torna por completo iguais, apresentando assim suas peculiaridades. A partir disso pode-se afirmar que tanto igualdade quanto desigualdade são aplicadas apenas a determinadas propriedades do que ou quem se avalia (Velasco, 2009).

Ao tratar de forma distinta seres de uma mesma categoria surge a noção de equidade, pois esta surge quando levamos em consideração um aspecto presente nas pessoas da categoria que ao deixar outros aspectos de fora, se estes fossem considerados nos conduziriam a um julgamento diferente. Em outras palavras, a equidade pode ser vista como um meio de estabelecer a igualdade e assim produzir uma avaliação de forma justa para todos (Velasco, 2009).

Um exemplo de pesquisa envolvendo leis e Justiça é o trabalho de Percheron (1991) com jovens franceses. Uma análise fatorial das respostas revelou uma articulação existente entre as representações de justiça e lei. Foi possível apresentar quatro representações estruturadas de lei e Justiça construídas de forma social e contendo influencia de diversas variáveis, como por exemplo, a renda. Este foi um dos trabalhos pioneiros sobre Justiça envolvendo a Teoria das Representações Sociais na França no ano de 1987.

Shimizu e Menin (2004) apresentam um trabalho sobre as representações sociais dos termos lei, justiça e injustiça tanto envolvendo jovens brasileiros e argentinos. Os resultados apontam para uma forte relação entre os termos lei e justiça, uma vez que as evocações da pesquisa sugerem a lei como aplicada pela Justiça e esta assegurada pela lei. No que se refere ao terceiro termo, injustiça, este surge atrelado a termos centrais como desigualdade e corrupção.

Já Spadoni e Torres (2010) fizeram sua pesquisa com estudantes universitários de cursos de psicologia de Goiânia e Paris. Utilizando os termos indutores justiça e injustiça foi possível constatar representações sociais são apenas distintas, mas também opostas.

Existem diversas concepções de justiça, onde algumas defendem a distribuição do tratamento de forma igualitária a todos (a cada um a mesma coisa) e outras de forma proporcional na medida de suas desigualdades (a cada um segundo suas necessidades) (Velasco, 2009).

Uma definição mais ampla é apontada por Figueiredo (1997 p. 74), e segundo ele "justiça tem a ver segundo a qual benefícios e encargos, ganhos e perdas são distribuídos entre os membros de uma sociedade, como resultado do funcionamento de suas instituições: sistemas de propriedade, organização pública, etc.". 
De uma forma geral, existem duas grandes concepções de Justiça e ambas se relacionam a uma sociedade igualitária, mas calcadas em aspectos distintos: uma concepção mais individualizante e outra mais social.

Em sua concepção Rawls (2000) afirma que há dois princípios de Justiça, onde, no primeiro princípio cada pessoa teria direito igual; e no segundo princípio as desigualdades só são passíveis de existir se elas contemplarem todo o conjunto da sociedade e estiverem vinculadas a cargos e posições acessíveis a todos. Por se tratar de um modelo de governo baseado em dois grandes princípios de liberdade e igualdade distributiva de direitos e deveres que são regidos por instituições essa concepção de Justiça seria mais individualizante.

Fraser (2002) e Sousa Santos (2008) postulam em sua concepção de Justiça Social que esta se relaciona à distribuição de recursos e de renda; e também ao reconhecimento das contribuições variadas dos diferentes grupos sociais e da diferença presente neles (Neves \& Lima, 2007; Piovesan, 2008; Lima, 2010).

No que se refere às cotas, a concepção de Justiça compartilhada pelos jovens é uma possível explicação da frequente rejeição das cotas encontrada em diversos estudos, como de Naiff et al. (2009) entre outros. Segundo a pesquisa de Neves e Lima (2007) os posicionamentos estão intrinsicamente ligados à concepção de justiça do estudante. A ideia é que o posicionamento que se tem das cotas envolve o que a pessoa pensa sobre justiça. Assim, as diferentes concepções de Justiça direcionariam as representações e consequentemente os posicionamentos acerca da reserva de vagas.

A partir deste trabalho de Neves e Lima (2007) foram utilizadas na presente pesquisa duas concepções de Justiça, que não são as únicas, mas foram as escolhidas para a verificação de sua relação com os posicionamentos por abarcarem o pensamento das pessoas no senso comum.

A primeira concepção, chamada Justiça Individualizante ou Clássica, é herdada do iluminismo, e a regra é que todos os indivíduos devem ser tratados em total igualdade e somente suas aptidões e desempenhos devem ser ponderados. Na segunda concepção, chamada Justiça Social ou Coletivista, os indivíduos são aceitos como vivendo em condições diferentes e, caso o coletivo acredite que uma diferenciação possa ser benéfica para todos, a discriminação pode ser aceita para garantir que haja condições que levem a uma concorrência igual.

Na pesquisa aqui contemplada, a respeito das cotas no pensamento do senso comum dos estudantes, acredita-se que se encontrando uma relação entre as concepções de justiça dos estudantes e suas avaliações das cotas chegar-se-á possivelmente à compreensão da rejeição das cotas nas representações dos estudantes universitários.

\section{Método}

Este trabalho possui como objetivo a busca pela compreensão da rejeição das cotas para negros por universitários, como observado em estudos anteriores (Naiff et al., 2009; Neves \& Lima, 2007; Silva \& Silva, 2012). Para tanto, tendo em vista a possível relação das concepções de justiça e posicionamentos, objetivou-se levantar as concepções de Justiça dos estudantes universitários, tanto estudantes cotistas quanto não cotistas e observar as 
relações entre as distintas concepções de Justiça e os posicionamentos em relação às cotas para negros. Sendo assim, para atender a estes objetivos o método abarca entrevistas semiestruturadas, realizadas com sujeitos de três Universidades distintas e suas informações coletadas foram tratadas por análise de conteúdo.

\section{Participantes}

A pesquisa foi feita com estudantes universitários de ambos os sexos selecionados por estarem matriculados em diferentes cursos de graduação e por apresentarem algum posicionamento referente às cotas raciais, ou seja, ser favorável, desfavorável ou neutro. Participaram 14 estudantes com idade média de 22,6 anos, sendo 9 do sexo feminino e 5 do sexo masculino. Destes 14 universitários, 4 são cotistas e 10 não cotistas.

Os sujeitos são 7 estudantes da Universidade do Estado do Rio de Janeiro (UERJ), 4 da Universidade Federal Rural do Rio de Janeiro (UFRRJ) e 3 da Universidade Federal de Uberlândia (UFU). No que se refere aos cursos, 10 participantes são estudantes do curso de psicologia enquanto 4 realizam outra graduação: engenharia civil, física, direito e enfermagem. Esta divisão entre cursos ocorreu para que uma maior heterogeneidade de opiniões pudesse aparecer nos resultados.

Os sujeitos foram divididos por seu posicionamento em relação às cotas raciais com: 4 sujeitos desfavoráveis, 4 favoráveis e 6 neutros. O número de sujeitos neutros em relação às cotas raciais é maior por se tratar de um caso de difícil aferição. Cabe ressaltar que neutros seriam os participantes que possuem conhecimento acerca das cotas raciais, mas dizem não ter posicionamento porque não querem ou não sabem se posicionar ou ainda aqueles que não têm conhecimento acerca das cotas raciais e não sabem ou não querem se posicionar.

Acerca do cruzamento dos posicionamentos e cursos dos participantes é válido salientar que dos 4 estudantes desfavoráveis às cotas raciais 3 são do curso de psicologia e 1 do curso de engenharia civil; dos 4 estudantes favoráveis às cotas raciais 3 são do curso de psicologia e 1 do curso de física; e dos estudantes neutros 4 são do curso de psicologia, 1 do curso de direito e 1 do curso de enfermagem.

\section{Características da entrevista}

Com o objetivo de coletar dados referentes ao pensamento social dos universitários foram realizadas entrevistas semiestruturadas. Estas abarcam perguntas tanto abertas quanto fechadas e possibilitam limitar o volume das informações coletadas além de promover melhor direcionamento ao tema pesquisado (Boni \& Quaresma, 2005).

Entrevistas semiestruturadas apresentam um roteiro de questões gerais acerca de um assunto proposto pelo pesquisador a todos os sujeitos cujas informações serão coletadas. Os dados podem ser analisados de forma quantitativa ou qualitativa a partir de gravações e transcrições (Pádua, 2004).

O uso desse instrumento se deu pela elasticidade quanto à sua duração e abrangência das respostas frente ao tema, já que os entrevistados estariam à vontade para discorrer livremente sobre as questões apresentadas. Para Boni e Quaresma (2005) trata-se da semelhança com uma conversa informal, o que permite ao entrevistado falar abertamente 
acerca do assunto e possibilita ao entrevistador corrigir equívocos de compreensão do conteúdo coletado, o que não seria possível com questionários, por exemplo.

O tempo médio das entrevistas foi de 15 minutos, e elas foram realizadas nos laboratórios de pesquisa das próprias universidades. O roteiro possui 23 questões que foram elaboradas a partir de discussões no Laboratório de Memórias e Representações Sociais (MEMORES) da UERJ e a partir de uma vasta revisão de literatura na qual argumentos mais frequentes relativos às cotas foram selecionados.

A estruturação do roteiro de entrevistas (ANEXO 1) compreende 3 blocos de questões: o bloco 1 abarca perguntas que visem deixar o sujeito mais familiarizado com o ambiente da pesquisa, ou seja, mais à vontade. Cabe dizer que essas questões não foram analisadas; o bloco 2 traz questões sobre justiça a partir de ponto de vistas mais sociais ou individualizantes, são perguntas que visavam obter informações referentes às ou à concepção de justiça do estudante; e o bloco 3 apresenta questões sobre as cotas em gerais. Ao final desses blocos existem os argumentos pró e contra cotas raciais e sociais levantados a partir da literatura e também de forma original a fim de apresenta-los a cada sujeito para que racionalize seu posicionamento e o justifique.

Assim, de acordo com o grau de aceitação das cotas foram apresentados argumentos contrários a fim de fazer com que o sujeito racionalizasse seu posicionamento. Ou seja, aos sujeitos desfavoráveis foram apresentados argumentos a favor das cotas e aos favoráveis, argumentos contra. No caso dos neutros foram exibidos ambos os argumentos relativos aos dois extremos, pró e contra as cotas raciais.

\section{Análise de dados}

A análise de dados compreende a análise de conteúdo de Bardin (2000), caracterizada por um conjunto de técnicas de análise das comunicações que descreve o conteúdo das mensagens de forma clara, sistemática e objetiva. É possível realizar esta análise a partir de qualquer material de comunicação, sejam fontes escritas, faladas, visuais, independe de serem verbais ou não, como por exemplo: fotografias, jornais, livros, filmes, cartas, entre outros (Moraes, 1999).

No presente trabalho a análise de conteúdo foi realizada a partir de fontes verbais, as entrevistas, e as etapas da análise são as citadas por Bardin (2000) e sistematizadas por Oliveira (2008): pré-análise, cuja tarefa consistiu em preparar e selecionar o conteúdo da análise; exploração do material ou codificação, na qual os dados foram agregados em unidades de registro que possibilitaram a descrição exata do conteúdo manifesto, e também foram incluídas em unidades de significação inseridas em categorias; e tratamento dos resultados, inferência e interpretação, onde as informações obtidas na análise foram quantificadas a partir de frequências.

\section{Resultados}

A análise de conteúdo das 14 entrevistas obteve um total de 144 unidades de registro contabilizadas e inseridas em 55 unidades de significação que, por sua vez, foram incluídos em 21 categorias. Os resultados dos entrevistados (favoráveis, desfavoráveis ou neutros em relação às cotas raciais) foram divididos em unidades de significação e categorias, como demonstrados nas tabelas 1 e 2 . 
Tabela 1 - Resultados relativos às respostas dos universitários quando indagados sobre sua opinião a respeito do conceito de justiça

\begin{tabular}{|c|c|c|c|c|}
\hline Categorias & Unidades de Significação & $\begin{array}{l}\text { Favoráveis } \\
\text { às cotas } \\
\text { para negros }\end{array}$ & $\begin{array}{c}\text { Desfavoráveis } \\
\text { às cotas para } \\
\text { negros }\end{array}$ & $\begin{array}{c}\text { Neutros às } \\
\text { cotas para } \\
\text { negros }\end{array}$ \\
\hline \multirow{2}{*}{$\begin{array}{l}\text { CONCEPÇÃO DE JUSTIÇA } \\
\text { SOCIAL }\end{array}$} & $\begin{array}{l}\text { Justiça é igualar as pessoas na } \\
\text { medida da desigualdade delas }\end{array}$ & \multirow{2}{*}{2} & \multirow{2}{*}{0} & \multirow{2}{*}{3} \\
\hline & $\begin{array}{l}\text { Justiça é ter todos os benefícios e } \\
\text { direitos garantidos socialmente }\end{array}$ & & & \\
\hline \multirow{7}{*}{$\begin{array}{l}\text { DIMENSÃO INDIVIDUAL DA } \\
\text { JUSTIÇA }\end{array}$} & Justiça é considerar a & \multirow{7}{*}{3} & \multirow{7}{*}{2} & \multirow{7}{*}{8} \\
\hline & individualidade de cada um & & & \\
\hline & $\begin{array}{l}\text { Justiça é igualar as pessoas na } \\
\text { medida da desigualdade delas }\end{array}$ & & & \\
\hline & $\begin{array}{l}\text { Justiça é não quebrar as regras que } \\
\text { permitem que haja a individualidade } \\
\text { de cada um }\end{array}$ & & & \\
\hline & Injustiça é falta de caráter & & & \\
\hline & Justiça é ser coerente & & & \\
\hline & Justiça relacionada ao caráter & & & \\
\hline \multirow{4}{*}{$\begin{array}{l}\text { VALORIZAÇÃO } \\
\text { IGUALDADE EM JUSTIÇA }\end{array}$} & $\begin{array}{l}\text { Justiça é analisar as partes } \\
\text { envolvidas e tentar achar um meio } \\
\text { termo que não prejudique ninguém }\end{array}$ & \multirow{4}{*}{6} & \multirow{4}{*}{4} & \multirow{4}{*}{4} \\
\hline & Justiça é a prática da igualdade & & & \\
\hline & Justiça é igualdade & & & \\
\hline & $\begin{array}{l}\text { Justo é levar em conta todos os } \\
\text { fatos }\end{array}$ & & & \\
\hline \multirow{2}{*}{$\begin{array}{l}\text { JUSTIÇA COMO ALGO } \\
\text { ABSOLUTO }\end{array}$} & Justiça de Deus & \multirow{2}{*}{0} & \multirow{2}{*}{2} & \multirow{2}{*}{3} \\
\hline & Justiça é fazer o certo & & & \\
\hline \multirow{3}{*}{$\begin{array}{l}\text { JUSTIÇA } \\
\text { RELATIVO }\end{array}$} & $\begin{array}{l}\text { Justiça é fazer o que se acha que é o } \\
\text { certo }\end{array}$ & \multirow{3}{*}{0} & \multirow{3}{*}{7} & \multirow{3}{*}{0} \\
\hline & Justiça pode ser feita por cada um & & & \\
\hline & Não existe um parâmetro & & & \\
\hline \multirow{3}{*}{$\begin{array}{l}\text { JUSTIÇA COMO ÓRGÃO } \\
\text { SUPERIOR }\end{array}$} & Justiça é estar na lei & \multirow{3}{*}{1} & \multirow{3}{*}{1} & \multirow{3}{*}{1} \\
\hline & Justiça é um órgão superior & & & \\
\hline & Justiça é a lei & & & \\
\hline $\begin{array}{l}\text { DIFICULDADE } \\
\text { JUSTIÇA }\end{array}$ & Dificuldade de definir justiça & 1 & 4 & 4 \\
\hline OUTROS & Justo é não impor limites & 0 & 1 & 1 \\
\hline Total & & 13 & 21 & 24 \\
\hline
\end{tabular}

Conforme é possível observar na tabela 1, há um total de 58 unidades de registro e 22 unidades de significação abarcados em 8 categorias. Os participantes favoráveis possuem menor número de unidades de registro se comparados aos demais participantes, e em sua concepção de justiça demonstram não a pensar de forma absoluta ou relativa. Por sua vez os participantes neutros apresentam unidades em todas as categorias, exceto "Justiça como algo relativo".

No que se refere ao questionamento do conceito de justiça, os três grupos presentes na pesquisa ressaltam a noção de igualdade relacionada à justiça. Os sujeitos favoráveis às 
cotas raciais apresentam maiores frequências nas categorias relativas à concepção de justiça social e também à dimensão individual da justiça.

Os participantes desfavoráveis não apresentam frequências na categoria relativa à concepção de justiça social. Juntamente aos neutros, os contrários apresentam em suas respostas dificuldade de definir justiça e justiça como algo absoluto. A maior frequência dos participantes desfavoráveis está na categoria "Justiça como algo relativo", seguido de "Valorização da igualdade em justiça". Além disso, surge nas respostas destes participantes a "Dimensão individual da justiça".

As maiores frequências de respostas dos neutros estão nas categorias "Dimensão individual da justiça", "Valorização da igualdade em justiça" e "dificuldade de definir justiça". Esses sujeitos apresentam uma maior quantidade de respostas que os outros grupos isto possivelmente traduz uma maior dispersão de suas ideias.

Tabela 2 - Resultados relativos às respostas dos universitários quando indagados sobre sua opinião a respeito das cotas para negros em Universidades

\begin{tabular}{|c|c|c|c|c|}
\hline Categorias & Unidades de significação & $\begin{array}{l}\text { Favoráveis } \\
\text { às cotas } \\
\text { para negros }\end{array}$ & $\begin{array}{l}\text { Desfavoráveis } \\
\text { às cotas para } \\
\text { negros }\end{array}$ & $\begin{array}{l}\text { Neutros às } \\
\text { cotas para } \\
\text { negros }\end{array}$ \\
\hline \multirow{2}{*}{$\begin{array}{l}\text { AS COTAS DEVEM ABRANGER } \\
\text { SOMENTE AS CONDIÇÕES } \\
\text { SOCIOECONÔMICAS }\end{array}$} & $\begin{array}{l}\text { As cotas devem abranger somente } \\
\text { as condições socioeconômicas }\end{array}$ & \multirow[b]{2}{*}{0} & \multirow[b]{2}{*}{5} & \multirow[b]{2}{*}{0} \\
\hline & $\begin{array}{l}\text { Negros podem entrar por cotas de } \\
\text { alunos oriundos de escola pública }\end{array}$ & & & \\
\hline \multirow{6}{*}{ REJEIÇÃO DAS COTAS RACIAIS } & $\begin{array}{l}\text { A avaliação das cotas deve ser } \\
\text { mais global }\end{array}$ & \multirow{6}{*}{0} & \multirow{6}{*}{5} & \multirow{6}{*}{3} \\
\hline & Contrário às cotas para negros & & & \\
\hline & Cotas são desnecessárias & & & \\
\hline & $\begin{array}{l}\text { Existe preconceito mas as cotas } \\
\text { não são necessárias }\end{array}$ & & & \\
\hline & $\begin{array}{l}\text { Não há justificativa para às cotas } \\
\text { para negros }\end{array}$ & & & \\
\hline & Contrário às cotas raciais & & & \\
\hline \multirow{2}{*}{$\begin{array}{l}\text { ACEITAÇÃO } \\
\text { RACIAIS }\end{array}$} & Defesa das cotas para negros & \multirow{2}{*}{7} & \multirow{2}{*}{0} & \multirow{2}{*}{2} \\
\hline & Favorável às cotas raciais & & & \\
\hline \multirow{3}{*}{$\begin{array}{l}\text { COTAS GERAM } \\
\text { DISCRIMINAÇÃO }\end{array}$} & $\begin{array}{l}\text { Cotas promovem ainda mais a } \\
\text { discriminação }\end{array}$ & \multirow{3}{*}{0} & \multirow{3}{*}{2} & \multirow{3}{*}{3} \\
\hline & Cotas inferiorizam os beneficiados & & & \\
\hline & $\begin{array}{l}\text { Talvez as cotas promovam ainda } \\
\text { mais a discriminação }\end{array}$ & & & \\
\hline \multirow{2}{*}{$\begin{array}{l}\text { O PASSADO DAS MINORIAS } \\
\text { NÃO INTERFERE NO PRESENTE }\end{array}$} & $\begin{array}{l}\text { O passado dos negros não } \\
\text { influencia no presente }\end{array}$ & \multirow[b]{2}{*}{2} & \multirow[b]{2}{*}{2} & \multirow{2}{*}{0} \\
\hline & $\begin{array}{l}\text { O passado dos negros não } \\
\text { interfere no presente }\end{array}$ & & & \\
\hline TODOS SÃO IGUAIS & Todos somos iguais & 0 & 2 & 0 \\
\hline \multirow{4}{*}{ NECESSIDADE DE IGUALDADE } & Existe discriminação no país & \multirow{4}{*}{4} & \multirow{4}{*}{0} & \multirow{4}{*}{4} \\
\hline & O mundo é para todos & & & \\
\hline & $\begin{array}{l}\text { Cotas são medidas válidas para a } \\
\text { promoção da igualdade }\end{array}$ & & & \\
\hline & $\begin{array}{l}\text { O problema da desigualdade com } \\
\text { os negros não se resume à } \\
\text { educação }\end{array}$ & & & \\
\hline $\begin{array}{l}\text { COTAS FACILITAM A INSERÇÃO } \\
\text { NA SOCIEDADE }\end{array}$ & $\begin{array}{l}\text { As cotas influenciam na inserção } \\
\text { na universidade e também na } \\
\text { saída }\end{array}$ & 8 & 0 & 2 \\
\hline
\end{tabular}


Continuação - Tabela 2

\begin{tabular}{|c|c|c|c|c|}
\hline \multirow{3}{*}{ MISCIGENAÇÃO } & Existe o problema de miscigenação & \multirow{3}{*}{5} & \multirow{3}{*}{0} & \multirow{3}{*}{0} \\
\hline & Miscigenação & & & \\
\hline & Todo mundo no Brasil é pardo & & & \\
\hline $\begin{array}{l}\text { O PASSADO DOS NEGROS } \\
\text { INTERFERE NO PRESENTE }\end{array}$ & $\begin{array}{l}\text { O passado dos negros interfere no } \\
\text { presente }\end{array}$ & 1 & 0 & 3 \\
\hline \multirow[b]{2}{*}{$\begin{array}{l}\text { REPRESENTATIVIDADE NEGRA } \\
\text { NA UNIVERSIDADE }\end{array}$} & $\begin{array}{l}\text { A Universidade deve refletir a } \\
\text { diversidade da população }\end{array}$ & \multirow[b]{2}{*}{0} & \multirow[b]{2}{*}{0} & \multirow[b]{2}{*}{2} \\
\hline & $\begin{array}{l}\text { Os negros devem estar na } \\
\text { Universidade para representar } \\
\text { essa parcela da população }\end{array}$ & & & \\
\hline $\begin{array}{l}\text { COTAS SÃO VÁLIDAS COMO } \\
\text { MEDIDA PROVISÓRIA }\end{array}$ & $\begin{array}{l}\text { Cotas são necessárias como } \\
\text { medidas provisórias }\end{array}$ & 0 & 0 & 4 \\
\hline \multirow{4}{*}{$\begin{array}{l}\text { DIFICULDADE DE AVALIAÇÃO E } \\
\text { APLICAÇÃO DAS COTAS } \\
\text { RACIAIS }\end{array}$} & $\begin{array}{l}\text { Dificuldade de avaliação das cotas } \\
\text { para negros }\end{array}$ & \multirow{4}{*}{0} & \multirow{4}{*}{0} & \multirow{4}{*}{15} \\
\hline & $\begin{array}{l}\text { O sistema de cotas necessita de } \\
\text { reformulação }\end{array}$ & & & \\
\hline & Cotas são parcialmente boas & & & \\
\hline & Neutro às cotas raciais & & & \\
\hline OUTROS & $\begin{array}{l}\text { As cotas facilitam a inserção no } \\
\text { vestibular mas não na correção } \\
\text { das provas }\end{array}$ & 0 & 0 & 1 \\
\hline Total & & 27 & 16 & 43 \\
\hline
\end{tabular}

Já na tabela 2, observa-se um total de 86 Unidades de registro e 33 unidades de significação abarcadas em 14 categorias. Quando questionados sobre sua opinião referente às cotas para negros, os sujeitos neutros às cotas raciais possuem maior número de respostas na categoria relacionada à dificuldade de avaliação das cotas raciais e levantam a questão da necessidade de igualdade e a defesa das cotas como medidas provisórias.

Interessante notar que estas unidades de significação relativas à dificuldade de avaliação mostram os sujeitos neutros, que citam tanto argumentos comuns aos sujeitos favoráveis quanto desfavoráveis, com consciência de sua ambiguidade. Além disso, os participantes neutros também verbalizam ideias relacionadas à rejeição das cotas e a associam ao aumento de discriminação.

De fato, apresentar argumentos opostos ao posicionamento dos sujeitos no momento das entrevistas pode ter influenciado no aumento da frequência total das unidades de registro dos neutros, pois talvez esse total de respostas seja maior que dos outros participantes por haver mais argumentos apresentados a estes, já que por serem 'indecisos' eram exibidas tanto falas contrárias quanto favoráveis ao entrevista-los.

Os sujeitos desfavoráveis apesar de rejeitarem as cotas raciais demonstram certo grau de aceitação de cotas sociais. Eles também levantam argumentos relacionados à igualdade, discriminação e alegam que não há interferência do passado nas condições atuais das minorias.

O conteúdo das respostas dos participantes favoráveis abarca a defesa das cotas raciais e aspectos relacionados à eficácia destas, pois promove o acesso aos negros a meios fundamentais como acesso à educação e permite uma melhor inserção social. Contudo, a questão da miscigenação é apontada como dificuldade deste tipo de cotas no Brasil. 
Também estão presentes nas respostas argumentos relacionados à igualdade e discriminação.

Ambos os posicionamentos polarizados, favoráveis e desfavoráveis às cotas raciais, levantam a ideia de igualdade em suas respostas, todavia sob aspectos distintos. Enquanto os que defendem a ideia das cotas como medidas válidas para promoção da igualdade, os participantes contrários as criticam por considerar que estas ferem o princípio de igualdade, já que oferecem tratamento distinto entre as pessoas. Esses são argumentos comuns frequentes na literatura das cotas (Guimarães, 2003; Oliven, 2007).

\section{Discussão}

É possível observar nos resultados da pesquisa a dificuldade de definir justiça, com baixas frequências e poucas unidades de significação, o que também é notado na literatura (Sandel, 2012). Possivelmente isto traduziria o fato de que Justiça não seria um objeto de representações sociais, mas sim outra forma do pensamento social.

As representações sociais são teorias ingênuas sobre algo, no entanto estes participantes não possuem tal tipo de concepção. A noção de Justiça parece ser algo mais afetivo e pouco cognitivo. Em outras palavras, frente à justiça há a indignação, revolta, esperança, desejo e anseio por esta, mas pouca concepção.

Estes objetos pouco cognitivos e muito afetivos se aproximam, segundo Wolter (2009), do conceito de nexus elaborado por Rouquette em 1994. Estes nexus correspondem aos objetos do pensamento social que são mais sentidos que pensados e frequentemente se associam às mobilizações coletivas e manifestações. Alguns trabalhos mais recentes demonstram que frente à esta classe de objetos os participantes tendem a perder a capacidade de racionalização (Wolter \& Rouquette, 2010) e a notar menos diferenças intragrupais (Lo Monaco, Rateau \& Guimelli, 2007).

No que diz respeito ao conceito de igualdade, este aparece nas respostas dos universitários atrelado ao termo justiça, como também se nota em outros trabalhos (Neves \& Lima, 2007; Velasco, 2009). É comum que participantes contrários apresentem como argumento que as cotas ameaçam à noção de igualdade, enquanto os favoráveis alegam que as cotas possibilitam a justiça social, na medida em que equipam as diferenças e assim promovem igualdade (Lima et al., 2014). Ou seja, ambos os posicionamentos levantam a questão igualitária como fundamental na avaliação de justiça, todavia esta é compreendida de forma muito distinta entre eles. Este caso nos remete às relações entre dois objetos de pensamento social, justiça e igualdade.

Quanto aos neutros, que abarcam respostas típicas dos dois posicionamentos extremos, favoráveis e desfavoráveis, postula-se que o que ocorreu é a chamada polifasia cognitiva, apresentada por Moscovici (1978) como uma característica do pensamento natural onde, numa mesma pessoa coexistem diferentes modos de pensar. Isto porque os entrevistados neutros verbalizam ideias distintas relativas aos dois grupos polarizados. Ou seja, eles compartilham da lógica das ideias dos participantes que rejeitam e defendem as cotas raciais.

A ambivalência dos sujeitos neutros é compatível aos resultados de Silva e Silva (2012) onde os estudantes da Universidade Federal da Bahia (UFBA) ressaltam a eficácia das cotas, 
mas também afirmam que não seria a melhor medida para as diferenças presentes na sociedade. Da mesma forma os neutros afirmam que as cotas são válidas para promoção da igualdade, mas também as defendem como medidas provisórias. Eles afirmam que a política é parcialmente boa ao mesmo tempo que pensam que o sistema necessitaria de reformulações.

No que se refere às cotas para negros os participantes favoráveis ressaltam a influência destas na inserção da vida universitária e também profissional dos cotistas, enquanto os sujeitos desfavoráveis apontam o caráter socioeconômico das cotas, pois acreditam que esta deveria ser a única condição de abrangência dessa medida. Esse é um argumento bastante comum na literatura (Oliven, 2007; Almeida, 2007).

Além disso, tanto os participantes que apoiam quantos os que criticam as cotas raciais parecem ter sua dimensão atitudinal referente às cotas muito acentuada, pois verbalizam muito seus posicionamentos, apesar de não mencionarem na mesma medida questões relacionadas à justiça.

Os resultados aqui mencionados abarcam alguns fatores da discussão levantada por Neves e Lima (2007), uma vez que os sujeitos da pesquisa reconhecem as dificuldades da minoria negra e a eficácia das cotas, mas preferem avaliações mais individualizantes ao invés de medidas de discriminação positiva focadas em determinado grupo social.

O conteúdo da análise das entrevistas referente aos sujeitos que defendem as cotas raciais traz esta política como um meio possível para equiparar as diferenças e promover a igualdade. Esse resultado se assemelha a pesquisa feita com universitários da Universidade Federal da Bahia (UFBA) de Melo, Dantas, Fernandez, Pereira e Chaves (2014).

O fato dos universitários que criticam as cotas raciais apresentarem nos resultados uma visão de justiça relativista, onde ser justo pode ser fazer o que se tem por certo, nos leva ao estudo de Queiroz e Santos (2006), onde os autores apresentam a frequente oposição às cotas como um meio de manutenção de privilégios de uma elite social. Ou seja, é possível que 'ser justo e fazer o que se tem por certo' se relacione diretamente com as necessidades individuais de cada um, e não com a necessidade de todos.

De fato, há o reconhecimento que existe desigualdade social, mas as divergências surgem ao discutir como seria a intervenção a fim de garantir a mobilidade desses grupos na sociedade, e os argumentos dividem-se em: justiça distributiva por parte do Estado e meritocracia/individualismo (Scalon, 2007).

No caso das cotas não é diferente. Parece que há uma divergência clara entre o conteúdo das entrevistas dos diferentes posicionamentos frente às cotas. E por discordarem dos meios para equiparar as desigualdades os sujeitos levantam questões muito distintas, ao ponto de às vezes fazerem referência a um mesmo conceito, mas com concepções opostas, como a noção de igualdade.

\section{Conclusões}

De uma forma geral os resultados traduziram o pensamento peculiar das pessoas com os três tipos de posicionamento em relação às cotas raciais. De fato, o campo de estudos das representações sociais possibilitou dissertar acerca do assunto uma vez que as 
representações estão ligadas às práticas, onde estas modificam o pensamento e este também as modifica.

No caso das cotas ocorre o mesmo, pois elas deixaram de ser apenas uma lei, tornando-se parte do cotidiano dos universitários, e demandando deles algum tipo de opinião acerca do assunto. Por se tratar de um objeto polêmico e atrelado à noção de justiça, estas adquiriram um caráter muito afetivo, mobilizando diferentes grupos sociais, como professores e estudantes. De fato, os universitários sabem se posicionar acerca das cotas com clareza e tem dimensão quanto à neutralidade ou não sobre o assunto, o que não ocorre com o conceito de justiça.

Vale ressaltar que o que se buscou foi colaborar, a partir de ferramentas psicossociais, para a compreensão da frequente rejeição das cotas raciais por parte de universitários levantando o pensamento social destes frente a estas, bem como contribuir para este debate tão polêmico e atual que precisa ser pesquisado por envolver o campo da educação e também a dimensão social de grupos minoritários.

Por fim, assim como outros estudos psicossociais os resultados apontaram que a estrutura do pensamento dos universitários frente às cotas se encontra atrelada ao conceito de justiça. A partir desses dados entende-se a necessidade de investigar as causas desses posicionamentos frente às cotas.

\section{Referências}

Abric, J. C. (2000). A abordagem estrutural das representações sociais. Estudos interdisciplinares de representação social, 2(1998), 27-38.

Almeida, M. M. (2007). Ações afirmativas: dinâmicas e dilemas teóricos entre a redistribuição e reconhecimento. Il Seminário nacional e movimentos sociais, participação e democracia, 25-27.

Bardin, L. (2000). Análise de conteúdo. Lisboa: Edições 70.

Bergmann, B. (1996). In defense of affirmative action. New York: BasicBooks.

Boni, V., \& Quaresma, S. J. (2005). Aprendendo a entrevistar: como fazer entrevistas em Ciências Sociais. Em Tese, 2(1), 68-80.

Brasil (2000). Decreto no 3.524, de 26 de junho de 2000. Regulamenta a Lei no 7.797, de 10 de julho de 1989, que cria o Fundo Nacional do Meio Ambiente e dá outras providências. Brasília, DF.

Brasil (2012). Lei no 12.711, de 29 de agosto de 2012. Dispõe sobre o ingresso nas universidades federais e nas instituições federais de ensino técnico de nível médio e dá outras providências. Brasília, DF.

De Sousa Santos, B. (2008). Para uma revolução democrática da justiça. São Paulo: Cortez.

Figueiredo, A. C. (1997). Princípios de justiça e avaliação de políticas. Lua Nova, 39, 73-103.

Fraser, N. (2002). A justiça social na globalização: redistribuição, reconhecimento e participação. Revista crítica de ciências sociais, (63), 07-20.

Gomes, J. B. (2003). O debate constitucional sobre as ações afirmativas. In R. E. Santos \& F. Lobato (Orgs.). Ações afirmativas: Políticas públicas contra as desigualdades raciais. Rio de Janeiro: DP\&A.

Guimarães, A. S. A., \& Souza, J. (1997). A desigualdade que anula a desigualdade: notas sobre a ação afirmativa no Brasil. Multiculturalismo e racismo: uma comparação Brasil-Estados Unidos. Paralelo, 15, 233-242.

Guimarães, A. S. A. (2003). Acesso de negros às universidades públicas. Cadernos de Pesquisa, 118, 247-268. 
Jaccoud, L. (2008). Racismo e república: o debate sobre o branqueamento e a discriminação racial no Brasil. In M. Theodoro (Org.). As políticas públicas e as desigualdades raciais no Brasil 120 anos após a abolição (pp. 45-64). Brasília: IPEA.

Jodelet, D. (2001). Representações sociais: um domínio em expansão. In D. Jodelet (Org.). As representações sociais (pp. 17-44). Rio de Janeiro: EdUerj.

Kowarick, L. (1994). Trabalho e vadiagem: a origem do trabalho livre no Brasil. Editora Brasiliense.

Lima, A. M. D. (2010). Justiça em Nancy Fraser. Dissertação de Mestrado, Universidade Federal do Piauí, Teresina, PI, Brasil.

Lima, M. E. O., Neves, P. S. C., \& Silva, P. B. (2014). A implantação de cotas na universidade: paternalismo e ameaça à posição dos grupos dominantes. Revista Brasileira de Educação, 19(56), 141-163.

Lo Monaco, G., Rateau, P., \& Guimelli, C. (2007). Nexus, représentations sociales et masquage des divergences intra et intergroupes. Bulletin de psychologie, 492(6), 581-592.

Melo, C. V. G., Dantas, G. S., Fernandez, Z. M. B., Pereira, M. E., \& Chaves, A. M. (2014). Representações sociais de estudantes da UFBA sobre as cotas universitárias. Psicologia e Saber Social, 3(1), 55-69.

Menin, M. S. D. S., \& Souza, A. D. P. D. (2001). Representações sociais de lei em adolescentes de uma cidade de São Paulo. Temas em Psicologia,9(3), 199-210.

Menin, M. S. D. S. (2006). Representação social e estereótipo: a zona muda das representações sociais. Psicologia: teoria e pesquisa, 22(1), 43-51.

Moehlecke, S. (2002). Ação afirmativa: história e debates no Brasil. Cadernos de pesquisa, 117(11), 197-217.

Moraes, R. (1999). Análise de conteúdo. Revista Educação, 22(37), 7-32.

Moscovici, S. (1978). A representação social da psicanálise. Rio de Janeiro: Zahar.

Moscovici, S. (1979). Psychologie des minorités actives. Paris: PUF

Munanga, K. (2001). Políticas de ação afirmativa em benefício da população negra no Brasil: um ponto de vista em defesa de cotas. Sociedade e cultura,4(2), 31-43.

Naiff, D. G. M., Naiff, L. A. M., \& Souza, M. A. D. (2009). As representações sociais de estudantes universitários a respeito das cotas para negros e pardos nas universidades públicas brasileiras. Estudos e Pesquisas em Psicologia, 9(1).

Neves, P. S., \& Lima, M. E. O. (2007). Percepções de justiça social e atitudes de estudantes pré-vestibulandos e universitários sobre as cotas para negros e pardos nas universidades públicas. Revista Brasileira de Educação,12(34), 17-38.

Oliven, A. C. (2007). Ações afirmativas, relações raciais e política de cotas nas universidades: Uma comparação entre os Estados Unidos e o Brasil. Educação, 30(61), 29-51.

Oliveira, D. C. D. (2008). Análise de conteúdo temático-categorial: uma proposta de sistematização. Rev. enferm. UERJ, 16(4), 569-576.

Pádua, E. M. M. D. (2004). Metodologia da pesquisa: abordagem teórico-prática. Campinas-SP: Papirus.

Percheron, A. (1991). Représentations de la loi et de la justice chez les Français de 16 à 21 ans. Droit et société, 19(1), 377-388.

Pinto, P. G. H. R. (2005). Ação afirmativa, fronteiras raciais e identidades acadêmicas: uma etnografia das cotas para negros na UERJ. J. Feres \& J. Zoninsein (Orgs.). Ação afirmativa e universidade: Experiências nacionais comparadas (pp. 9-45). Brasília: Editora UnB.

Piovesan, F. (2008). Ações afirmativas no Brasil: desafios e perspectivas. Estudos Feministas, 16(3), 887-896.

Queiroz, D. M., \& Santos, J. T. D. (2006). Sistema de cotas: um debate. Dos dados à manutenção de privilégios e de poder. Educação e Sociedade,27(96), 717-737.

Rawls, J. (2000). Teoria da Justiça. Brasília: UnB. 
Rio de Janeiro (2001). Lei no 3708, de 09 de novembro de 2001. Institui cota de até 40\% (quarenta por cento) para as populações negra e parda no acesso à Universidade do Estado do Rio de Janeiro e à Universidade Estadual Do Norte Fluminense, e dá outras providências.

Rouquette, M.-L. (1994). Sur la connaissance des masses, essai de psychologie politique. Grenoble : Presses Universitaires de Grenoble.

Sá, C. P. (1993). Representações sociais: o conceito e o estado atual da teoria. In M. J. Spink (Org.). O conhecimento no cotidiano: as representações sociais na perspectiva da psicologia social (pp. 19-45). São Paulo: Editora Brasiliense.

Sá, C. P. (2007). As representações sociais na história recente e na atualidade da psicologia social. In A. M. JacóVilela, A. A. L. Ferreira \& F. T. Portugal (Orgs.). História da psicologia: rumos e percursos (pp. 587-602). Rio de Janeiro: Nau Editora.

Sandel, M. J. (2012). Justiça: o que é fazer a coisa certa. Rio de Janeiro: Editora José Olympio.

Scalon, C. (2007). Justice as equality: the perceptions of the brazilian elite and the people. Sociologias, (18), 126-149.

Schulz, J. (1994). O Exército na política: origens da intervenção militar, 1850-1894. São Paulo: Edusp.

Sell, S. C. (2002). Ação afirmativa e democracia racial: uma introdução ao debate no Brasil. Fundação Boiteux.

Shimizu, A. M., \& Menin, M. S. D. S. (2004). Representações sociais de lei, justiça e injustiça: uma pesquisa com jovens argentinos e brasileiros utilizando a técnica de evocação livre de palavras. Estudos de Psicologia,9(2), 239-247.

Silva, P. B., \& Silva, P. (2012). Representações sociais de estudantes universitários sobre cotas na universidade. Fractal, Rev. Psicologia, 24(3).

Spadoni, L. M., \& Torres, A. R. R. (2010). As ideias do senso comum sobre a relação entre a justiça e a injustiça. Aletheia, (31), 82-96.

Theodoro, M. (2008). A formação do mercado de trabalho e a questão racial no Brasil. As políticas públicas e a desigualdade racial no Brasil, 120, 15-43.

Tinhorão, J. R. (1988). Os sons dos negros no Brasil: cantos, danças, folguedos: origens. Editora 34.

Universidade de São Paulo (1996). Programa Nacional de Direitos Humanos. Universidade de São Paulo: Biblioteca Virtual de Direitos Humanos.

Vala, J., \& Monteiro, M. B. (2000). Representações sociais e psicologia do conhecimento. Psicologia Social, 4, 335-384.

Velasco, M. (2009). O que é justiça? O justo e o injusto na pesquisa filosófica. Um exemplo: as cotas raciais universitárias. Rio de Janeiro: Vieira \& Lent.

Wolter, R. M. C. P. (2009). Les objets à forte valence affective: la notion de nexus. In M-L. Rouquette (Ed.). La pensée sociale: Perspectives fondamentales et recherches appliquées. Ramonville St. Agne: Eres.

Wolter, R. M. C. P., \& Rouquette, M. L. (2010). Situations de crise et modes de raisonnement: effets de l'intensité du positionnement sur le choix d'un canevas de raisonnement. Les cahiers internationaux de psychologie sociale, 87(3), 479-489.

Wolter, R. M. C. P. (2011). Serge Moscovici: um pensador social. In A. M. de O. Almeida, M. de F. de S. Santos \& Z. A. Trindade (Orgs.). Teoria das Representações Sociais: 50 anos (pp. 21-29). Brasília: TechnoPolitik editora. 